\title{
Sobre el síndrome de Guillaín-Barré
}

\section{About the Guilláin-Barré syndrome}

\author{
Aldo Vivar-Merndoza ${ }^{\prime}$
}

\author{
Vivar-Mendoza A. Síndrome de Guillain-Barré. (Editorial). \\ Rev Soc Peru Med Interna. 2019;32(2):45-47. \\ https://doi.org//0.36393/spmi.v32i2.216
}

En el Perú, las epidemias son como los terremotos. Ocurren de improviso, generan miedo colectivo y dejan una sensación de precariedad de los servicios públicos. La mayor epidemia registrada en lo que va de 2019 tiene un nombre algo difícil de pronunciar, Guillain-Barré.

El recorrido histórico del llamado síndrome de GuillainBarré (SGB) es interesante, tanto como la evolución del concepto clínico. Los primeros casos de parálisis motora ascendente fueron descritos, en 1859, por Octave Landry. Cinco casos fueron propios y cinco de la literatura, y dos casos en los que se hizo autopsia no revelaron anormalidades en el cerebro o la médula espinal. ${ }^{1}$ Sin embargo, la literatura médica reconoce como fundacional el reporte de Guillain, Barré y Strohl, en 1916, en plena Primera Guerra Mundial, acerca de dos soldados con "dificultades motoras, pérdida de los reflejos osteotendinosos con preservación de los reflejos cutáneos, parestesias con leve deterioro de la sensibilidad, dolor muscular, alteraciones leves en la conducción nerviosa y los patrones electromiográficos así como un importante incremento en la albúmina del líquido cefalorraquídeo en ausencia de una reacción celular (disociación albúmino citológica)".2 Como se puede ver, la descripción original no difiere mucho de los criterios diagnósticos actuales.

En 1938, el mismo Guillain reconoció variantes clínicas del síndrome y propuso nuevos criterios de presentación: 1) de los miembros inferiores: 2) del tronco encefálico y médula espinal; 3) del diencéfalo; 4) polirradiculoneuropatía con alteración de la conciencia.

I Médico internista. Facultad de Medicina, Universidad Peruana Cayetano Heredia. Hospital Nacional Arzobispo Loayza, Lima.
En 1956, Miller Fisher presentó tres casos de una variante clínica caracterizada por oftalmoplejia total, ataxia y pérdida de los reflejos osteotendinosos asociados a una leve polineuropatía y a disociación albumino citológica muy similar a la variante diencefálica propuesta por Guillain. ${ }^{3}$

En 1960, ante la creciente confusión clínica con otras formas de polineuritis aguda se planteó la necesidad de establecer criterios diagnósticos para el síndrome. ${ }^{4} \mathrm{~A}$ lo largo de décadas, sucesivas publicaciones, reuniones de expertos y finalmente la formación de grupos de consenso clínico establecieron los necesarios criterios diagnósticos y las diversas formas clínicas del SGB, que en el camino dejó de lado los nombres de Strohl y Landry.

De acuerdo a la presentación clínica se establecieron dos grupos principales del SGB: la variante GuillainBarré (con formas sensitivas, motoras, paraparética o con parálisis facial bilateral) y la variante MillerFisher (con formas que incluyen ataxia, oftalmoplejia, ptosis palpebral o miosis). Estas formas comparten las alteraciones en la electromiografía y la clásica disociación albúmino citológica en el líquido cefalorraquídeo.

En el fondo, el concepto global del síndrome denota una enfermedad proteiforme con formas de presentación que pueden variar de paciente a paciente. El sustrato común es una reacción autoinmune dirigida contra la mielina-el evento fisiopatológico más común- o contra los axones. Aparentemente, una infección, por reacción antigénica cruzada, dispara la respuesta celular y humoral. Se han implicado diversas infecciones que actuarían como "disparadores": Campylobacter jejuni, 
citomegalovirus, virus de la hepatitis (A, B y E), enterovirus D68, Mycoplasma pneumoniae y virus del Zika, entre otros. Lo que quiere decir que no siendo el síndrome una enfermedad infecciosa ni contagiosa sería la expresión clínica de una infección.

En el año 2018, el Ministerio de Salud declaró una alerta sanitaria sobre un brote sospechoso de SGB, cuando se vio un número de casos no previsto que se inició en la costa norte del Perú, específicamente en La Libertad; entonces, se propusieron como probables disparadores a la infección por un eneterovirus o incluso el virus Zika. Lo poco publicado al respecto menciona que la parálisis era descendente o mixta y que los análisis de laboratorio no fueron concluyentes con la etiología. (5) No se tiene disponible un reporte final de los estudios clínicos, microbiológicos y epidemiológicos.

En lo que va de 2019, desde la semana epidemiológica 21 ( 19 al 25 de mayo) a la 24 (del 9 al 15 de junio) se reportó un acumulado de 263 casos de SGB en relación a los 14 casos reportados en las cuatro semanas previas. ${ }^{6}$ Este inusual incremento de casos que el ministerio considera "atípicos" llevó a las autoridades a declarar en estado emergencia sanitaria por 90 días en los departamentos de Piura, Lambayeque, La Libertad, Junín y Lima. Leyendo el reporte oficial se vislumbra que evita en todo momento nombrar este aumento inusual como epidemia.

Al 27 de junio, se han reportado 611 casos de SGB a nivel nacional, concentrados en los departamentos de Piura (111), Lambayeque (26), Cajamarca (47), La Libertad (48), Ancash (9) Lima (205), Callao (7), Junín (115) y Huancavelica (10). Según la edad, 299 casos en pacientes de 30 a 59 años; 120 casos, de 60 a más años; 106 casos, de 15 a 29 años; 43 casos, en los grupos de edad de 0 a 11 años y de 12 a 17 años.

La alerta sanitaria incluía además líneas generales para la detección, reporte y manejo de casos. Siendo el SGB una condición que puede complicarse con falla ventilatoria y muerte, las recomendaciones incluyen el manejo de estos pacientes en establecimientos de nivel 3 , es decir hospitales de referencia. Un portal web del Ministerio de Salud mostraba las directivas, estadísticas actualizadas, notas de prensa y una guía de manejo producida en 2018, en respuesta al brote epidémico de entonces que cualquier ciudadano puede consultar. ${ }^{6}$

La respuesta oficial podría calificarse de satisfactoria pero como la vida real es lo que sucede más allá de los documentos y oficinas gubernamentales hay algunas aristas de esta respuesta que son necesarias de decir.

Siendo los medios de comunicación masiva los vehículos más importantes de diseminación de información y viendo además que, aparte del canal oficial del Estado, dichos medios tienen un fin comercial, las noticias relativas a brotes o desastres tienen una connotación orientada al morbo que atrae sintonía pero que también siembra verdades a medias o miedos infundados. Si el nivel de lectoría de por sí es pobre, es bueno imaginar que un ciudadano de a pie no va a ingresar al portal del Ministerio de Salud a tomar información seria y de primera mano, sobre todo si el lenguaje y el sistema de navegación virtual no es amistoso con el visitante. Un comentario adicional es que cuando se mencionan los signos de alarma como parestesias o debilidad muscular se omitieron datos fundamentales: que los síntomas deben ser de inicio reciente (días) y la debilidad debe ser objetiva (es decir, incapacidad para realizar tareas cotidianas, no basta la sensación subjetiva). Esta información entregada a la población, involuntariamente genera alarma y ha empujado a algunas personas con síntomas crónicos, muchas veces subjetivos, a incrementar las consultas de los hospitales.

Como en todo brote de enfermedades, los casos declinan sin razón aparente; sin embargo, es importante tomar en cuenta algunas lecciones para una condición que aparentemente tiene una condición estacional, entre mayo y junio, así como geográfica, el centro y norte del país.

Si el disparador de los casos "atípicos" de SGB es una infección, se sabe que a nivel poblacional una infección tiene un número de personas asintomáticas y otras sintomáticas. De lo poca información clínica de los casos de 2018 y 2019 no se conoce que el cuadro neurológico esté asociado a síntomas respiratorios o gastrointestinales, por lo que a nivel clínico no es posible hacer más que conjeturas pero sin información de primera mano, que los organismos competentes poseen pero que la comunidad científica desconoce, no será posible tener una mejor idea de cómo actuar en situaciones similares a futuro. El país mantiene, a pesar del crecimiento económico, notables deficiencias en la higiene pública, tanto del riesgo a infecciones entéricas como respiratorias, una tarea transversal a varios ministerios del Estado.

Del mismo modo, las guías clínicas, en su versión corta y larga, han cumplido escrupulosamente con 
los requisitos burocráticos y estadísticos, pero su lectura tiene un valor más académico que práctico, no se destaca qué hacer según niveles de atención. Más aun, existe un claro sesgo profesional, los médicos responsables de la elaboración de estas guías proceden del Instituto Nacional de Ciencias Neurológicas, no han sido convocados expertos en medicina interna, cuidados intensivos o de bancos de sangre y hemoterapia, quienes en otros establecimientos de salud del Estado son los encargados de atender y manejar los casos hospitalizados del SGB. Una revisión de las guías, asimismo, revela información interesante pero pocas veces orientada al sentido práctico de cómo manejar un caso, más aun si tenemos en claro que estos casos son considerados "atípicos" y por la experiencia previa no se ha medido la efectividad de las terapias utilizadas en el pasado brote de 2018. En los hospitales del Ministerio de Salud, los pacientes con SGB son manejados en los servicios de medicina interna y en la unidad de cuidados intensivos, especialidades que no aparecen en los documentos oficiales.

Con el paso del tiempo, nuevos actores se han incorporado al manejo de la salud pública, muchos organismos se han potenciado y otros nuevos han aparecido como el Seguro Integral de Salud y Susalud. Cómo deben interactuar en beneficio de los afectados y del correcto desempeño de las labores hospitalarias es algo que aún se extraña y deja una sensación de precariedad en la organización donde quien atiende directamente se convierte en el eslabón más débil y quien asume la responsabilidad de todo el sistema.

Ahora que el brote de SGB del presente año se está desvaneciendo, es hora para recopilar y analizar la información obtenida para que sea convertida en aprendizaje de la experiencia, que sea difundida y discutida en los espacios correspondientes, sobre todo por los profesionales que históricamente asumen la responsabilidad directa de la atención sanitarias e las personas y no se convierta en un episodio más donde solo quedan documentos incompletos pero no lecciones aprendidas.

\section{REFERENCIAS BIBLIOGRÁFICAS}

I. Landry O.Note sur la paralysie ascendante aigue. Gazette Hebdomadaire Med Chir. 1859;6:472-88.

2. Guillain G, Barré JA, Strohl A. Sur un syndrome de radiculo-ne' vrite avec hyperalbuminose du liquide ce'phalo-rachidien sans re'action cellulaire. Remarques sur les caracte'res cliniques et graphiques des re'flexes tendineux. Bull Soc Med Hop Paris. 1916;40:1462-70.

3. Fisher, M.An unusual variant of acute idiopathic polyneuritis (syndrome of ophthalmoplegia, ataxia and areflexia). N Engl J Med. 1956;255:57-65.

4. Osler L, Sidell A. The Guillain-Barré Syndrome. The need for exact diagnostic criteria. N Engl J Med. 1960;262:964-969.

5. Ministerio de Salud. Centro Nacional de Epidemiología, Prevención y Control de Enfermedades 2018. Alerta epidemiológica AE 0II-2019. http://www.dge.gob.pe/portal/docs/alertas/2019/AE0II.pdf (ingresado el 27 de junio de 2019)

6. https://www.dge.gob.pe/portal/index.php?option=com content\&view=article\&id=652 (ingresado el 27 de junio de 2019) 